\title{
Afterbody Heating Predictions for a Mars Science Laboratory Entry Vehicle
}

\author{
Karl T. Edquist ${ }^{*}$ \\ NASA Langley Research Center, Hampton, Virginia, 23681
}

The Mars Science Laboratory mission intends to deliver a large rover to the Martian surface within $10 \mathrm{~km}$ of its target site. One candidate entry vehicle aeroshell consists of a 3.75-m diameter, 70-deg sphere-cone forebody and a biconic afterbody similar to that of Viking. This paper presents computational fluid dynamics predictions of laminar afterbody heating rates for this configuration and a 2010 arrival at Mars. Computational solutions at flight conditions used an 8-species Mars gas model in chemical and thermal non-equilibrium. A grid resolution study examined the effects of mesh spacing on afterbody heating rates and resulted in grids used for heating predictions on a reference entry trajectory. Afterbody heating rate reaches its maximum value near $0.6 \mathrm{~W} / \mathrm{cm}^{2}$ on the first windward afterbody cone at the time of peak freestream dynamic pressure. Predicted afterbody heating rates generally are below $3 \%$ of the forebody laminar nose cap heating rate throughout the design trajectory. The heating rates integrated over time provide total heat load during entry, which drives thermal protection material thickness.

\section{Nomenclature}

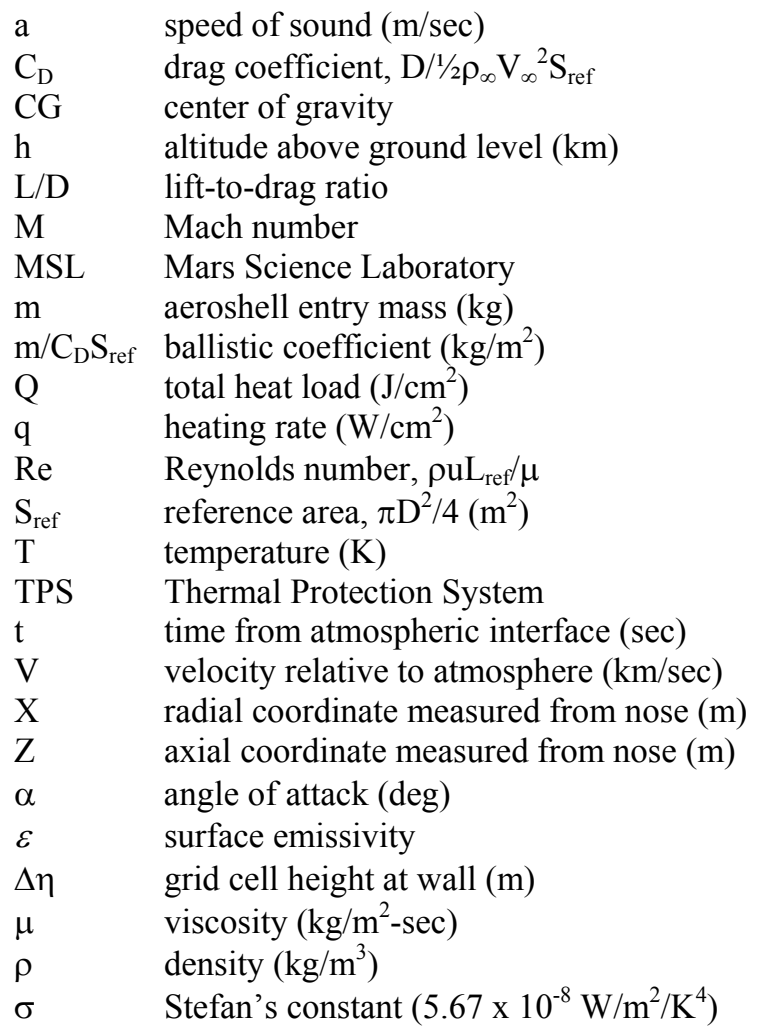

\footnotetext{
*Aerospace Engineer, Exploration Systems Analysis Branch, Mail Stop 466, AIAA Senior Member.
} 


\author{
Subscripts \\ D aeroshell diameter \\ SG Sutton-Graves formula \\ nose forebody nose cap \\ w wall \\ $\infty \quad$ freestream condition
}

\title{
I. Introduction
}

The Viking, Pathfinder, and Mars Exploration Rover missions successfully used ballistic entry trajectories to land on Mars with target accuracy on the order of $100 \mathrm{~km}$. Second generation landers, such as the proposed Mars Science Laboratory (MSL), will be designed to land with $10 \mathrm{~km}$ or smaller footprints that are of particular scientific interest $^{1,2}$. MSL will achieve $10 \mathrm{~km}$ landing accuracy through the use of lift via an offset radial center of gravity (CG). Controlling the entry vehicle lift mitigates uncertainties in predicted entry states, atmospheric properties, aerodynamics, etc. that cause an unguided entry to have a large landing footprint. A hypersonic lift-to-drag ratio (L/D) of 0.18 at a trim angle of attack $(\alpha)$ of 11 degrees and ballistic coefficient $\left(\mathrm{m} / \mathrm{C}_{\mathrm{D}} \mathrm{S}_{\mathrm{ref}}\right)$ less than $120 \mathrm{~kg} / \mathrm{m}^{2}$ are the desired entry conditions for a 2010 arrival. References 3-8 contain computational and experimental aeroheating analyses for various MSL entry vehicle configurations. Topics include predictions on alternative aeroshell shapes ${ }^{3}$, turbulent transition and heating augmentation ${ }^{4}$, and experimental studies in perfect gas and high-enthalpy facilities to augment and validate the computational results ${ }^{5-8}$.

This paper presents computed MSL laminar flight afterbody heating predictions and comparisons to perfect gas wind tunnel data. The prediction of afterbody heating rates is a difficult problem, even with improvements in computational tools and resources. Consequently, the uncertainties in predicted flight environments are typically much larger than those on the forebody. Even though afterbody heating rates are low, generally only a few percent of forebody heating levels, improvement in their prediction would help reduce entry mass. For Viking, the peak afterbody heating rate was predicted to be $3 \%$ (including a 1.5 factor of safety) of the nose laminar heating rate ${ }^{9}$. Post-flight analysis of the temperature data showed that the heating rates were as high as $4.2 \%$ of the nose laminar heating level. Since Viking, there have been few efforts to measure flight afterbody heating levels for Mars entry vehicles or compare modern computational methods to existing data ${ }^{10}$. The current effort is the first step in using high-fidelity computational tools to predict MSL afterbody heating environments and estimate the uncertainties in those predictions.

\section{Analysis}

\section{A. Aeroshell Geometry}

Figure 1 shows the candidate entry vehicle aeroshell geometry and dimensions. The vehicle is a $3.75-\mathrm{m}$ scaled version of the Viking 3.5-m 70-deg sphere-cone aeroshell ${ }^{11}$, with a blunter shoulder radius. A 70-deg sphere-cone has been the forebody shape of choice for all previous Mars entry aeroshells. Figure 2 shows a comparison of the MSL and Viking aeroshell shapes. The Viking entry vehicle also was designed to trim at $\alpha=11 \mathrm{deg}$ using an offset CG. The MSL afterbody cone angles are identical to those of Viking. The MSL aeroshell accommodates a larger rover than did Viking.

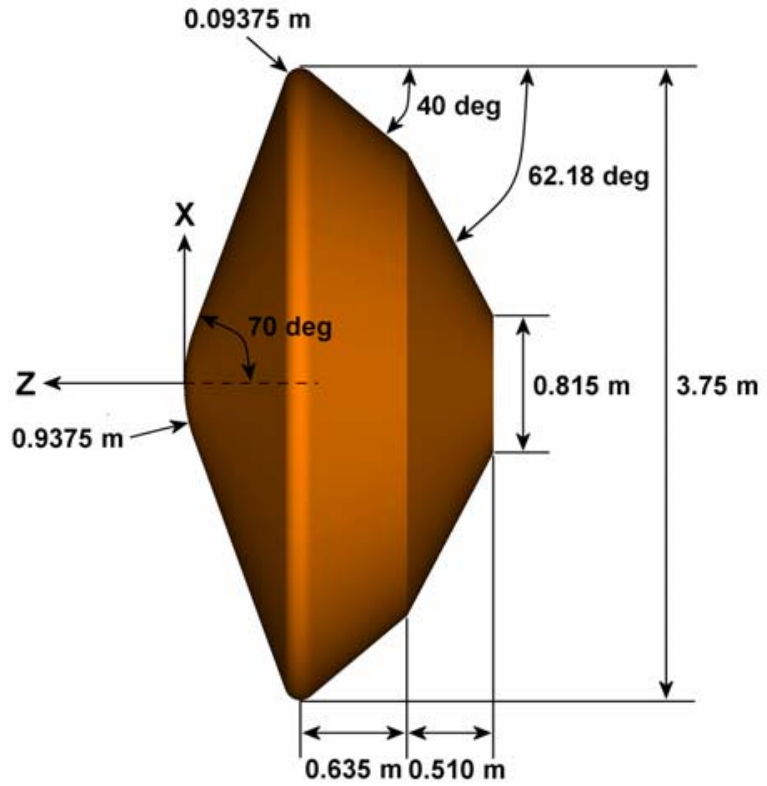

Figure 1. Aeroshell Geometry and Dimensions 


\section{B. Computational Method}

Computational Fluid Dynamics (CFD) modeling is combined with an experimental test program to predict the MSL flight vehicle aeroheating environments. Hypersonic flight conditions in a reacting Mars atmosphere cannot be recreated in ground-based facilities, so the use of numerical tools is a critical element of the MSL aeroheating analysis. The continued improvement of grid generation methods, flow solvers, and computational resources makes it possible to solve three-dimensional, chemically-reacting flowfields that once were prohibitive. The present analysis represents such an approach to predict afterbody flight aeroheating that cannot be duplicated in ground-based facilities. When available, ground-based data are used to validate the CFD models for perfect gas conditions.

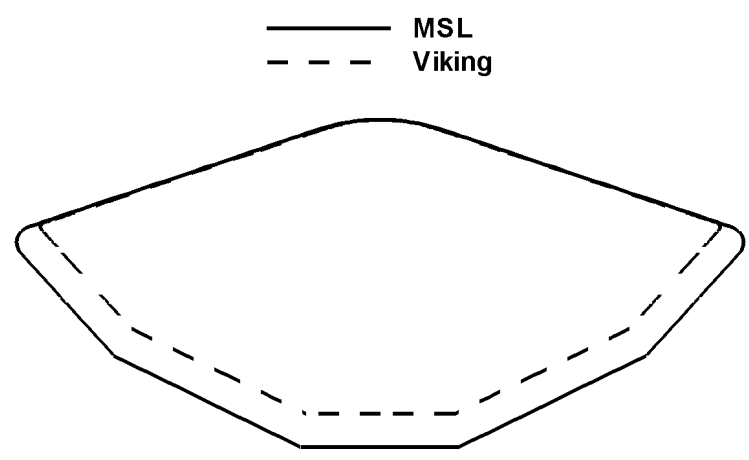

Figure 2. Comparison of MSL and Viking Entry Vehicle Aeroshell Shapes

\section{LAURA CFD Code}

Aeroheating calculations at flight conditions were performed using the Langley Aerothermodynamic $\underline{\text { Upwind }}$ Relaxation Algorithm (LAURA) ${ }^{12}$ CFD code. LAURA has been used previously to predict the aeroheating environments for other Mars applications ${ }^{13,14}$. For Mars flight conditions, LAURA models an 8-species Mars gas $\left(\mathrm{CO}_{2}, \mathrm{CO}, \mathrm{N}_{2}, \mathrm{O}_{2}, \mathrm{NO}, \mathrm{C}, \mathrm{N}, \mathrm{O}\right)$ in chemical and thermal non-equilibrium using the Park- $94^{15}$ reaction rates. A finite-volume approach is used to solve the full Navier-Stokes flowfield equations for all calculations presented here. The code uses Roe's averaging ${ }^{16}$ for the inviscid fluxes with second-order corrections using Yee's symmetric total variation diminishing (TVD) scheme ${ }^{17}$.

A super-catalytic wall boundary condition fixes the species mass fractions for $\mathrm{CO}_{2}$ and $\mathrm{N}_{2}$ at their freestream values of 0.97 and 0.03 , respectively. This boundary condition results in conservative heating rate predictions in flight. A radiative-equilibrium wall temperature was specified to satisfy the following relation:

$$
q_{w}=\varepsilon \sigma T_{w}^{4}
$$

A fixed surface emissivity $(\varepsilon)$ of 0.9 was used for all solutions. The wall is assumed to radiate to a temperature of absolute zero.

\section{Computational Grid}

LAURA solutions used a singularity-free structured volume grid of the reference configuration. Figure 3 shows the baseline surface and symmetry plane mesh distributions. Pitch plane symmetry allows modeling of only half of the aeroshell. The forebody nose cap and afterbody base meshes do not have a singularity pole boundary that could otherwise introduce artificial discontinuities into the flowfield. The finest streamwise grid resolution occurs at the shoulder and is necessary to resolve the rapidly expanding flow in that region.

The grids were built using GridGen ${ }^{18}$ to construct the topology and surface distribution, 3DGRAPE/AL ${ }^{19}$ to generate the volume grid, and the Volume Grid Manipulator (VGM) ${ }^{20}$ to enhance grid quality and impose boundary conditions along block interfaces. The baseline 56-block grid has 3280 surface cells and 64 cells in the surface normal direction. A grid resolution study examined meshes with finer resolution in all three coordinate directions. 

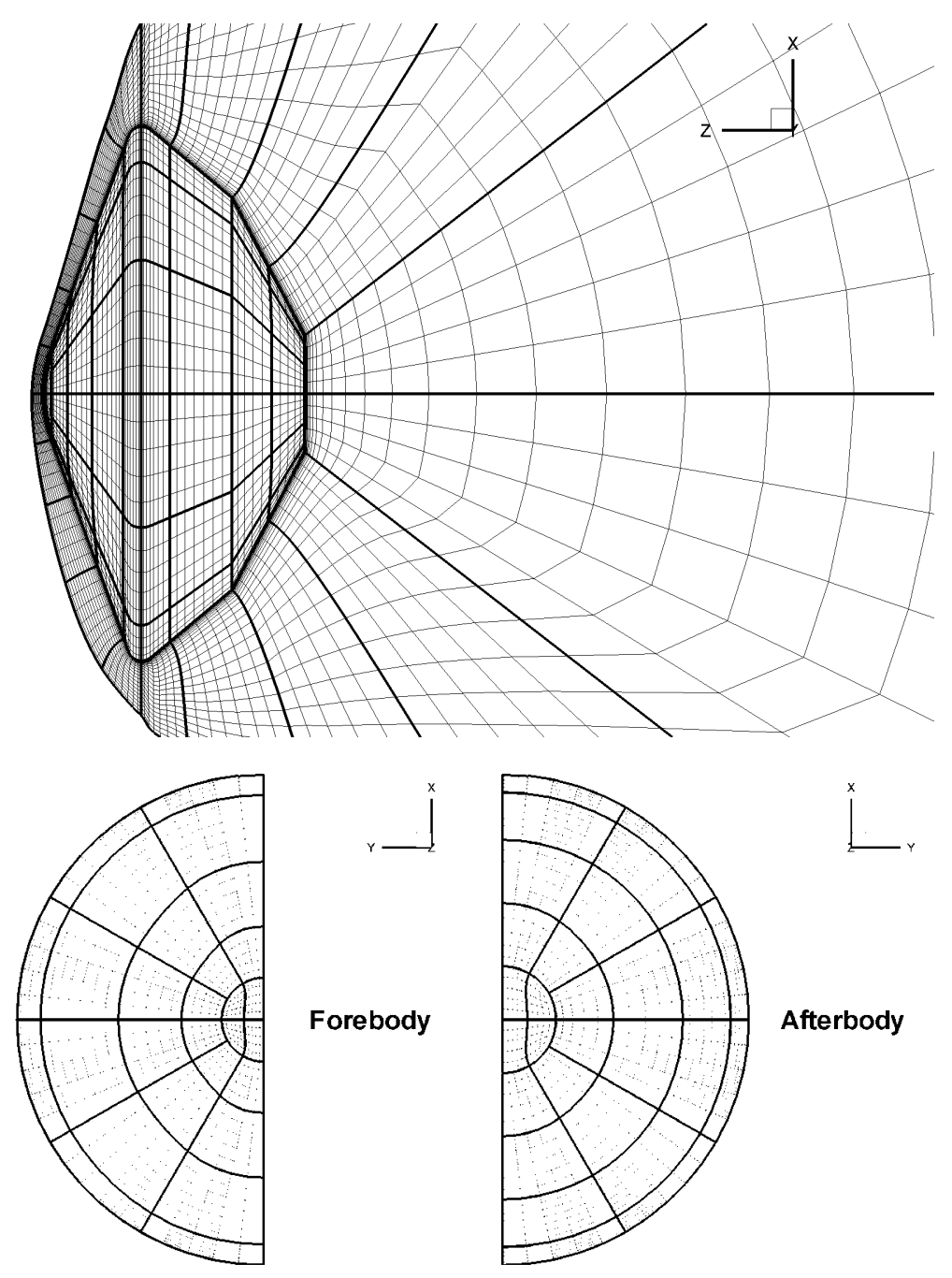

Figure 3. Baseline Symmetry Plane and Surface Computational Grid (Every Other Grid Point Shown in Each Direction)

\section{Grid Adaptation}

LAURA possesses the capability to adapt the computational mesh to the boundary layer and bow shock through user-defined parameters. Proper mesh resolution at the wall is especially important for reliable heating predictions. In LAURA, a user-specified cell Reynolds number controls the grid spacing at the wall:

$$
R e_{w}=\left(\frac{\rho a \Delta \eta}{\mu}\right)_{w}
$$

Experience has shown that reliable laminar heating predictions can be achieved with $\operatorname{Re}_{\mathrm{w}}=\mathrm{O}(1)$. Grid adaptations are executed throughout the solution process until further adaptations do not significantly change the heating rate.

\section{Atmospheric Entry Trajectory}

The MSL aeroheating analysis presented here is based on the $99.87 \%$ heat load trajectory for a 2010 arrival at Mars. The design trajectory was obtained through a Monte Carlo analysis of the entry system using Program to Optimize Simulated Trajectories $(\mathrm{POST})^{21}$. The analysis included uncertainties in navigation, mass properties, atmospheric density, and entry vehicle aerodynamics. Entry conditions for the specified trajectory are a $5.5 \mathrm{~km} / \mathrm{sec}$ 
atmosphere-relative velocity and a ** deg inertial flight path angle, The reference trajectory's integrated heat load was the 3 -sigma high case ( 99.87 percentile) of all cases run. Thermal protection system (TPS) material thickness, and thus mass, is proportional to the integrated heat load.

The MSL atmosphere-relative entry velocity is higher than Viking $\left(4.5 \mathrm{~km} / \mathrm{sec}\right.$, entry from orbit $\left.{ }^{9}\right)$, lower than Pathfinder $\left(7.47 \mathrm{~km} / \mathrm{sec}\right.$, direct entry $\left.{ }^{22}\right)$, and similar to the Mars Exploration Rovers $\left(5.5 \mathrm{~km} / \mathrm{sec}\right.$, direct entry $\left.{ }^{23}\right)$. Figure 4 shows the velocity-altitude map for the design trajectory. Reference heating rate, dynamic pressure, and Reynolds number based on aeroshell diameter $\left(\mathrm{Re}_{\mathrm{D}}\right)$ are shown in Figure 5. Atmospheric density perturbations included in the Monte Carlo analysis result in the plot line irregularities. The heating rate is based on the SuttonGraves $^{24}$ formula for a sphere having the same radius of curvature as the forebody nose. The peak heating rate occurs 89 seconds after atmospheric entry, followed by peak dynamic pressure at 110 seconds, and peak $\mathrm{Re}_{\mathrm{D}}$ at 120 seconds. LAURA solutions were obtained at eight time points along the trajectory, with freestream conditions summarized in Table 1. Freestream Conditions for CFD Solutions ( $\alpha=11 \mathrm{deg})$ Table 1.

\begin{tabular}{ccccccc}
\hline \hline $\mathrm{t}(\mathrm{sec})$ & $\mathrm{h}(\mathrm{km})$ & $\mathrm{V}(\mathrm{km} / \mathrm{sec})$ & $\rho\left(\mathrm{kg} / \mathrm{m}^{3}\right)$ & $\mathrm{T}(\mathrm{K})$ & $\mathrm{M}$ & $\mathrm{Re}_{\mathrm{D}}$ \\
\hline 50 & 68.3 & 5.54 & $4.71 \times 10^{-6}$ & 145 & 29.1 & $1.37 \times 10^{4}$ \\
70 & 47.7 & 5.48 & $7.63 \times 10^{-5}$ & 149 & 29.3 & $2.11 \times 10^{5}$ \\
80 & 38.3 & 5.31 & $2.10 \times 10^{-4}$ & 162 & 26.3 & $5.16 \times 10^{5}$ \\
89 & 31.0 & 4.98 & $4.74 \times 10^{-4}$ & 179 & 24.4 & $9.82 \times 10^{5}$ \\
103 & 22.3 & 4.10 & $1.05 \times 10^{-3}$ & 189 & 18.9 & $1.68 \times 10^{6}$ \\
109 & 19.6 & 3.63 & $1.44 \times 10^{-3}$ & 190 & 17.0 & $2.03 \times 10^{6}$ \\
113 & 18.0 & 3.32 & $1.48 \times 10^{-3}$ & 191 & 14.6 & $1.91 \times 10^{6}$ \\
137 & 14.2 & 1.95 & $2.43 \times 10^{-3}$ & 193 & 8.8 & $1.81 \times 10^{6}$ \\
\hline \hline
\end{tabular}

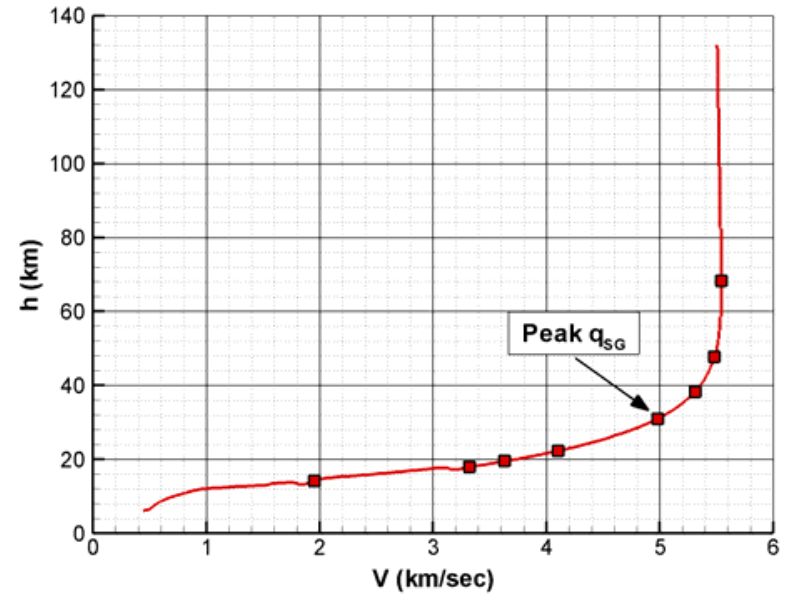

Figure 4. Altitude vs. Relative Velocity for the Reference Trajectory (Symbols Correspond to CFD Solution Points)

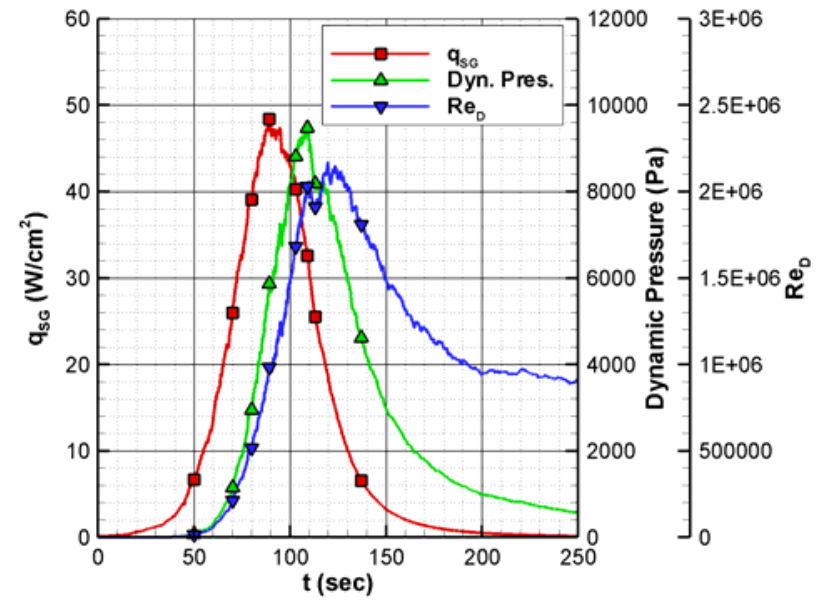

Figure 5. Reference Heating Rate, Dynamic Pressure, and Reynolds Number for the Reference Trajectory (Symbols Correspond to CFD Solution Points)

\section{Results and Discussion}

A grid resolution study was completed to determine the appropriate grid on which to compute flight predictions along the reference entry trajectory. The results of the grid study are shown along with afterbody heating rate predictions at various entry times and total integerated heat load.

\section{Grid Resolution Study}

Viscous CFD solutions require a large number of grid points and small spacing at wall boundaries in order to properly resolve the flowfield gradients. The complex features typical of blunt body wake flows make the grid requirements even more stringent for afterbody aeroheating predictions. The existence of unsteady flow, separation, 
and turbulence further complicate the numerical prediction of wake flowfields. Consequently, uncertainties on the predicted afterbody heating environments are typically much larger than those on the forebody.

A blunt body CFD grid must capture the essential flowfield features in order to produce dependable heating results. Figure 6 shows a typical blunt body flowfield at a hypersonic Mach number. At such high speeds, the shock wave lies very close to the forebody. The wake flowfield is influenced by the shear layer evolution from the shoulder. It is critical to capture the shear layer with sufficient streamwise and normal grid points so that the effects on recirculation and detachment are properly captured further downstream.

The objective of the grid

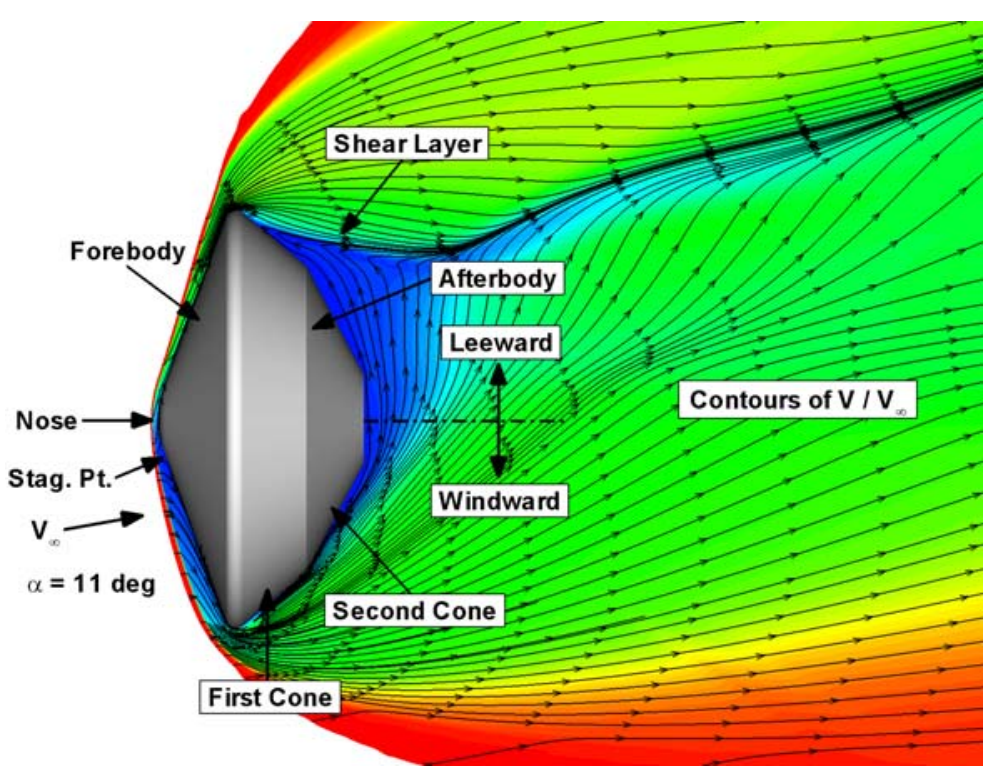

Figure 6. Hypersonic Flowfield Streamlines and Contours of Normalized Velocity resolution study was to determine the appropriate wall spacing in the surface normal direction and the streamwise spacing at the aeroshell shoulder. Wall spacing determines the quality of the resolved boundary layer. Shoulder streamwise spacing impacts the location of the shear layer, which in turn determines the evolution of flow separation/impingement and recirculation further downstream. The grid resolution study consisted of running several LAURA solutions at the time of peak Sutton-Graves heating rate on the reference trajectory. Beginning with the baseline grid, the grid distribution was resolved to finer levels in all directions until the peak afterbody heating rate remain unchanged with further grid refinement. Solutions at the remaining trajectory times used two meshes resulting from the grid resolution study, one "coarse" and one "fine"; a full grid resolution study was not performed for each trajectory point.

Table 2 summarizes the grids used in the resolution study, beginning with the baseline mesh (Grid 1). Each subsequent grid possesses twice the number of cells in the streamwise, circumferential, and/or normal direction for at least a portion of the grid. Special attention was paid to the resolution at the shoulder and on the first afterbody cone where rapid flow expansion occurs. For each grid, the average streamwise resolution around the aeroshell shoulder is reflected by the number of degrees of turning per streamwise cell. Figures 7 and 8 show the surface mesh distribution for the first four grids in the resolution study. Each surface grid was run with 64 and 128 cells in the surface normal direction. Grids 3 and 4 (not shown) contained four and eight times, respectively, the streamwise surface grid resolution of Grid 1 on the shoulder and first afterbody cone (blocks $23-40$ in Figure 8). Each grid was adapted to the boundary layer and bow shock within LAURA using the $\mathrm{Re}_{\mathrm{w}}$ specified in Table 2 .

Table 2. Grid Resolution Study

\begin{tabular}{ccccccc}
\hline \hline Grid & $\begin{array}{c}\text { Surface } \\
\text { Cells }\end{array}$ & $\begin{array}{c}\text { Normal } \\
\text { Cells }\end{array}$ & $\begin{array}{c}\text { Volume } \\
\text { Cells }\end{array}$ & $\operatorname{Re}_{\mathrm{w}}$ & $\begin{array}{c}\text { Avg. Deg./Cell } \\
\text { at Shoulder }\end{array}$ & Modification to Baseline Grid \\
\hline 1 & 3280 & 64 & 209,920 & 1 & 6.9 & Baseline \\
$1 \mathrm{a}$ & 3280 & 128 & 419,840 & 0.5 & 6.9 & 2x Normal \\
2 & 13120 & 64 & 839,680 & 1 & 3.5 & 4x Surface \\
$2 \mathrm{a}$ & 13120 & 128 & $1,679,360$ & 0.5 & 3.5 & 4x Surface and 2x Normal \\
3 & 17360 & 64 & $1,111,040$ & 1 & 1.7 & 4x Streamwise Shoulder \\
$3 \mathrm{a}$ & 17360 & 128 & $2,222,080$ & 0.5 & 1.7 & 4x Streamwise Shoulder and 2x Normal \\
4 & 27440 & 64 & $1,756,160$ & 1 & 0.8 & 8x Streamwise Shoulder \\
$4 \mathrm{a}$ & 27440 & 128 & $3,512,320$ & 0.5 & 0.8 & 8x Streamwise Shoulder and 2x Normal \\
\hline \hline
\end{tabular}




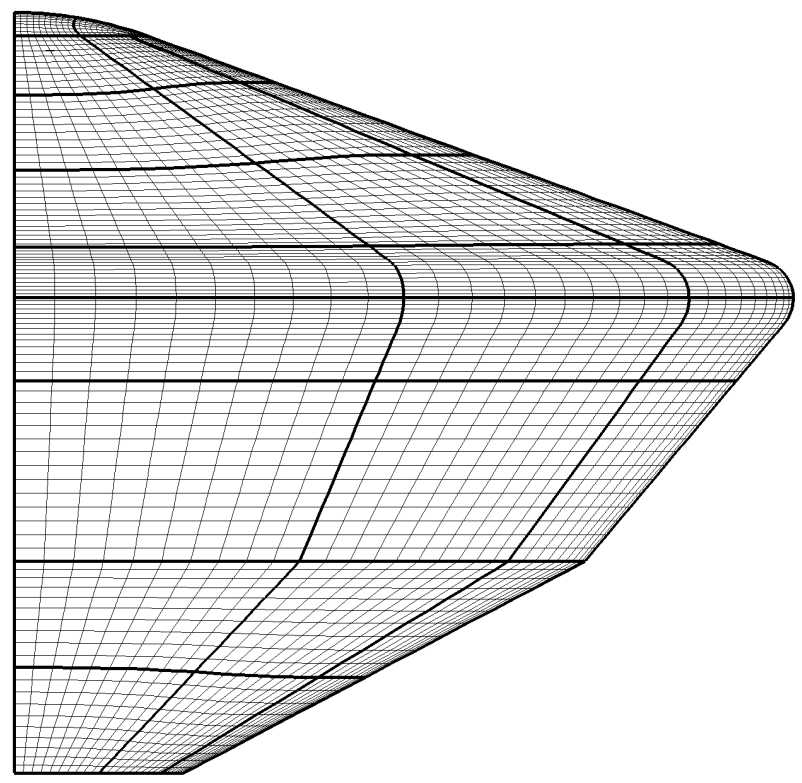

Figure 7. Surface Mesh for Grids 1 and 1a

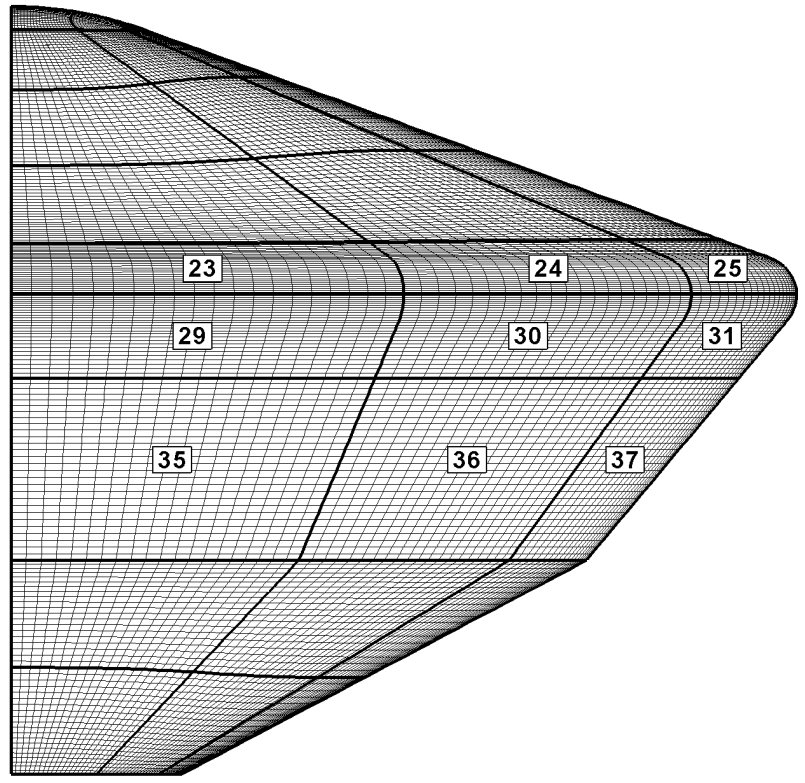

Figure 8. Surface Mesh for Grids 2 and 2a

Figures 9 and 10 show laminar windward afterbody heating rate, pressure, and shear stress as a function of radial coordinate for six of the eight grids in the resolution study. Figure 9 shows results for the first four grids. Peak afterbody heating rate occurs on the windward side of the first afterbody cone as the flow expands from the forebody. The predicted heating rate is nearly an order of magnitude lower at all other locations on the afterbody windward symmetry plane. The heating spikes at the windward shoulder (extreme left side) is ignored for the purposes of this study since it covers a relatively small area.

Figure 9 indicates that increasing normal and surface grid resolution separately (Grid 1a and 2) results in higher and lower heating rates, respectively, than the baseline level. The heating rates for Grid $1 \mathrm{a}$ and 2 are $+13 \%$ and $-11 \%$, respectively, from the Grid 1 results on the first afterbody windward cone at $X=-1.6 \mathrm{~m}$. Simultaneously doubling the grid resolution in all three coordinate directions (Grid 2a) results in heating rates $\mathrm{m}$ those on Grid 1. The same trends are reflected in the pressure and shear stress predictions; the results on Grids 1a and 2 bound the Grid 1 results. The pressures for Grid $1 \mathrm{a}$ and 2 are $+6 \%$ and $-10 \%$, respectively, from the Grid 1 results on the first afterbody windward cone at $X=-1.6 \mathrm{~m}$. The shear stress bounds at the same location are $+5 \%$ and $-4 \%$. Grid $2 \mathrm{a}$ produces pressure and shear stress distributions matching those on Grid 1, which is consistent with the heating rate results. All four grids predict attached flow along the entire first afterbody cone. The grid effects are more noticeable on the second cone where flow separation occurs. Flow separation is located at the point where pressures increases and shear stress decreases. Grid 1a predicts the earliest separation, and Grid 2 the latest. Heating rate is least affected by flow separation.

Figure 10 show the effects of increased streamwise resolution at the shoulder on heating rate, pressure, and shear stress. Further streamwise grid refinement at the shoulder and first afterbody cone (Grid 3a and Grid 4a) does not change the predicted heating rate on the first windward afterbody cone from the results of Grid 1 . The surface pressures and shear stress follow a similar trend. Again, there are small differences in the predicted flow separation point, with heating rate being the least affected. Grid 1 is the only grid with 64 normal cells that produces heating rates similar to those grids with 128 normal cells. It may be coincidental that the baseline grid resulted in the same heating rates on the first afterbody cone as the finest grids. Although Grid 1 produced grid independent heating on the first windward afterbody cone, both Grid 1 and Grid 2a were used for solutions at other time points to determine whether the finer grid produced significantly different results that did Grid 1 for other freestream conditions. The results are shown in the next section. Although not shown, increasing circumferential grid resolution does not affect predicted heating rate at $\alpha=11 \mathrm{deg}$. Circumferential grid distribution may become more important if $\alpha$ increases and more crossflow is induced. 

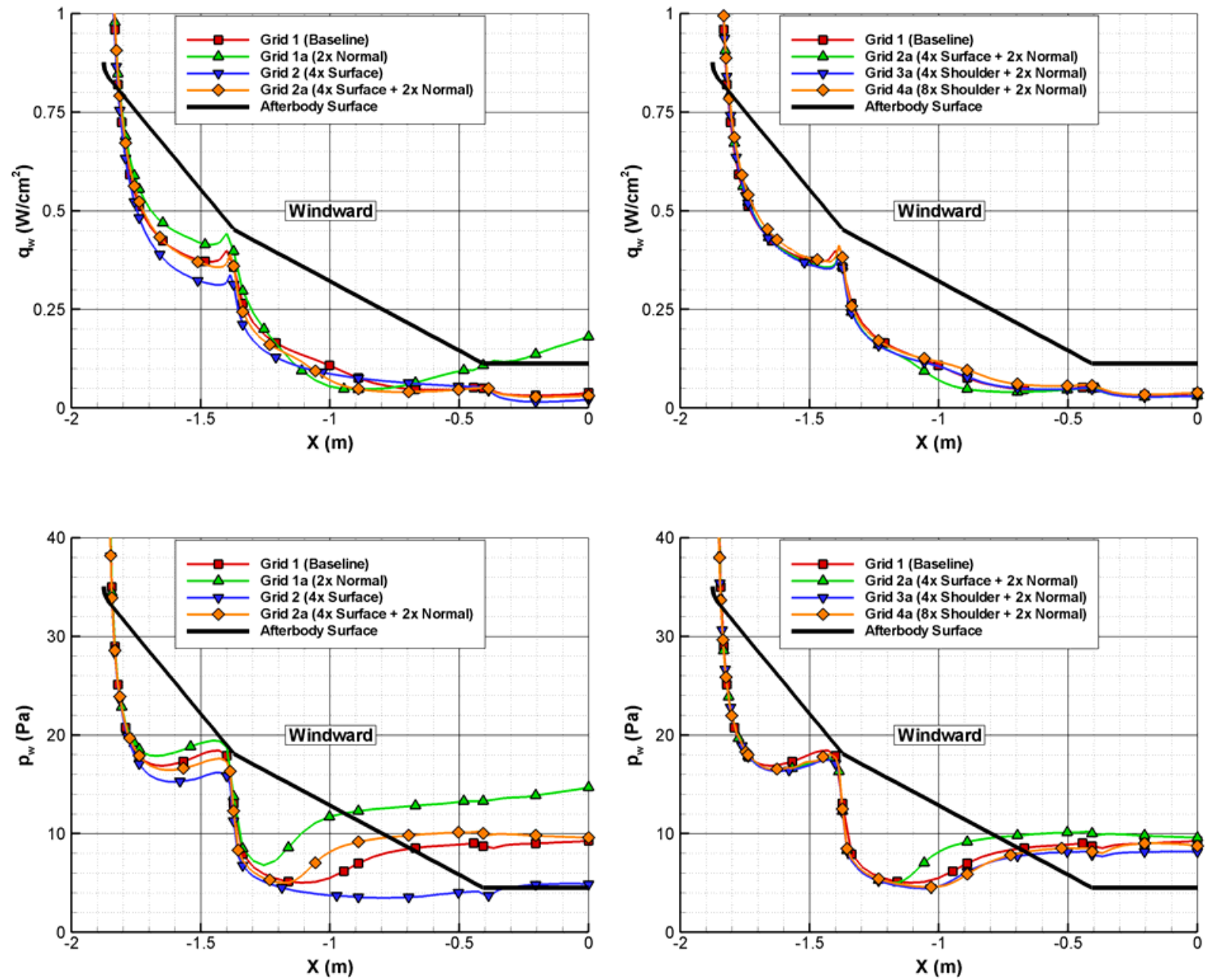

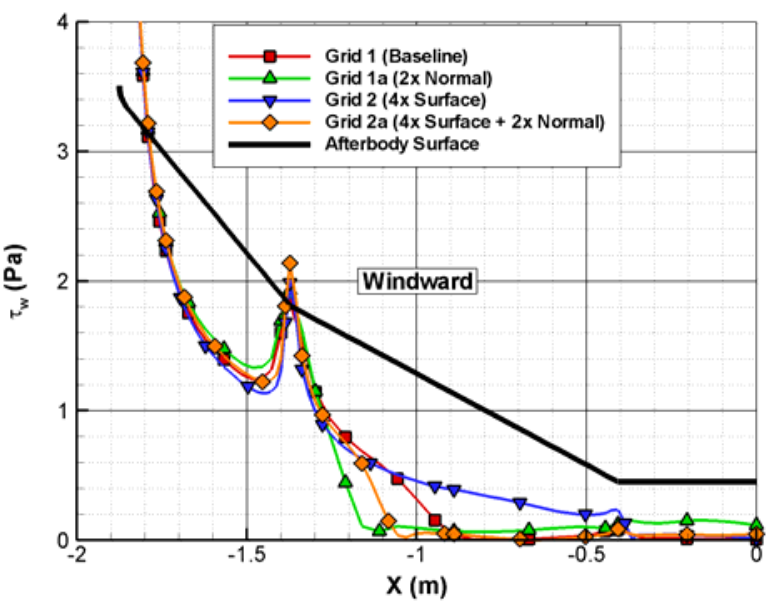

Figure 9. Effect of Grid Resolution on Computed Windward Afterbody Symmetry Plane Heating Rate (Top), Pressure (Middle), and Shear Stress (Bottom)

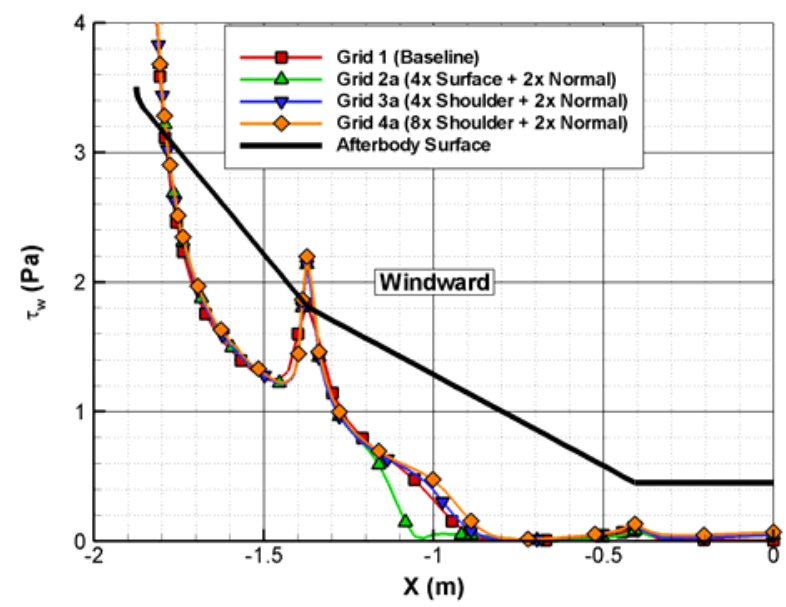

Figure 10. Effect of Streamwise Shoulder Grid Resolution on Computed Windward Afterbody Symmetry Plane Heating Rate (Top), Pressure (Middle), and Shear Stress (Bottom) 


\section{Flight Predictions}

Figure 11 shows the Grid 1 laminar heating rate distribution on the forebody and afterbody at 89 seconds. At a trim angle of 11 degrees, the stagnation point moves to a location near the tangency point between the spherical nose cap and conical flank. However, the maximum forebody heating rate of $44 \mathrm{~W} / \mathrm{cm}^{2}$ is still located on the apex of the nose cap. Turbulent transition is predicted to augment forebody heating higher than the laminar level shown ${ }^{5}$. The afterbody heating rates are two orders of magnitude lower than the forebody levels. As such, the backshell TPS thickness and mass are significantly smaller.

Computations at flight conditions were obtained on Grid 1 and Grid 2a to estimate peak afterbody heating rate and total integrated heat load for the reference trajectory. Figure 12 shows the

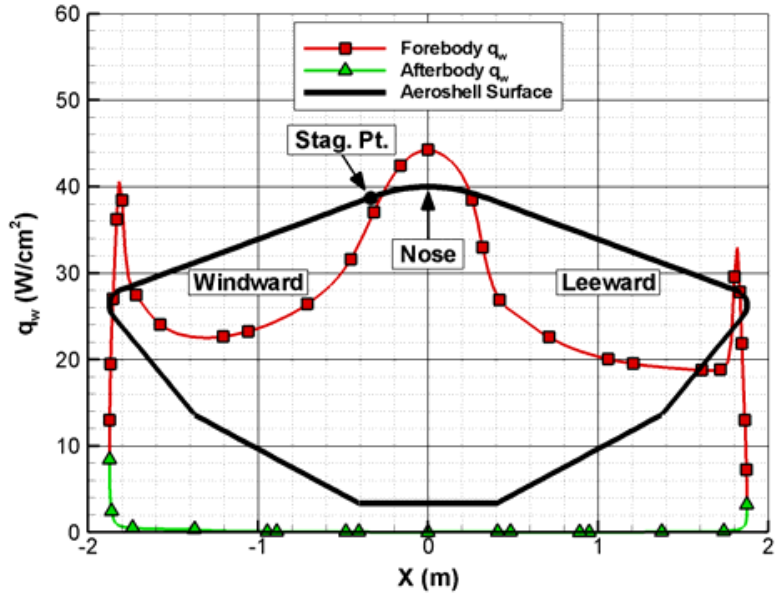

\section{Figure 11. Laminar Forebody and Afterbody Heating Rates at $\mathbf{t}=\mathbf{8 9}$ sec on the Reference Trajectory (Grid 1)}

streamlines and normalized velocity contours in the symmetry plane for each solution using Grid 1 . The shock standoff distance is smallest at 89 seconds at a Mach number of 24.4. With increasing time, the extent of the wake decreases and the origin of the leeward shear layer moves forward along the afterbody until it reaches the aeroshell shoulder. The flow is predicted to remain attached on the first windward afterbody cone at all times. At 103 seconds, as Reynolds number increases, the flow starts to detach at the second windward afterbody cone and secondary recirculation regions appear. The sensitivity in predicted heating rate to each grid adaptation was larger at the higher $\mathrm{Re}_{\mathrm{D}}$, possibly because the flow is actually unsteady even though the CFD solutions assume a steady state flowfield. This was especially true near the base of the vehicle where the windward flow separation occurs on the second afterbody cone.

Figure 13 shows the afterbody heating rate distributions on Grid 1 at various times along the reference entry trajectory. The peak heating rate for each time occurs on the windward first cone (left side). Heating on the remaining afterbody regions is generally much lower, except at 109 and 113 seconds where the Reynolds number is approaching its peak value. The maximum heating rate occurs at the time of peak dynamic pressure $(t=109 \mathrm{sec})$ rather than the time of peak Sutton-Graves heating rate $(t=89 \mathrm{sec})$. Heating rate magnitudes on the bulk of the windward first cone vary between $0.2 \mathrm{~W} / \mathrm{cm}^{2}$ and $0.6 \mathrm{~W} / \mathrm{cm}^{2}$.

Afterbody heating rate normalized by computed laminar nose heating rate is shown in Figure 14. Heating rate prior to peak dynamic pressure $(t=109 \mathrm{sec})$ is predicted to be below $1 \%$ of forebody nose heating for most of the afterbody. Beginning at $109 \mathrm{sec}$, the non-dimensional heating rate is higher, but still generally less than $3 \%$ of the laminar forebody nose level. The predicted normalized heating rates are in line with general rules of thumb for afterbody heating ( $\sim 2-5 \%$ of forebody heating). The predictions are also similar to Viking entry flight data ${ }^{3}$, which showed windward afterbody heating rates on the afterbody first cone up to $4.2 \%$ of forebody heating.

Figure 15 shows afterbody heating rate at $\mathrm{X}=-1.6 \mathrm{~m}$ as a function of time, along with Sutton-Graves heating rate and dynamic pressure. Again, the afterbody heating rate more closely mirrors freestream dynamic pressure than it does the heating rate. The heating rates between the two grids are within $5 \%$ of one another at most times, with the largest difference of $19 \%$ occurring at 137 seconds. The heating rates in Figure 14 were integrated over time $(0$ to 250 seconds) to obtain the total heat load shown in Figure 15. Results from both Grid 1 and Grid 2a are shown. Grid 2a heat load is up to 6\% lower on the first afterbody windward cone. The computed heat load is highest on the first windward cone, where it is generally between 40 and $100 \mathrm{~J} / \mathrm{cm}^{2}$. Heat load at other afterbody locations are lower, except for small regions near the aeroshell shoulder. The design heating environments will include uncertainties on the model predictions as well as uncertainties and margins for the TPS material response. Typical afterbody heating uncertainties are much larger than forebody heating uncertainties due to the complexity of wake flowfields, including unsteady flow and turbulence effects. 

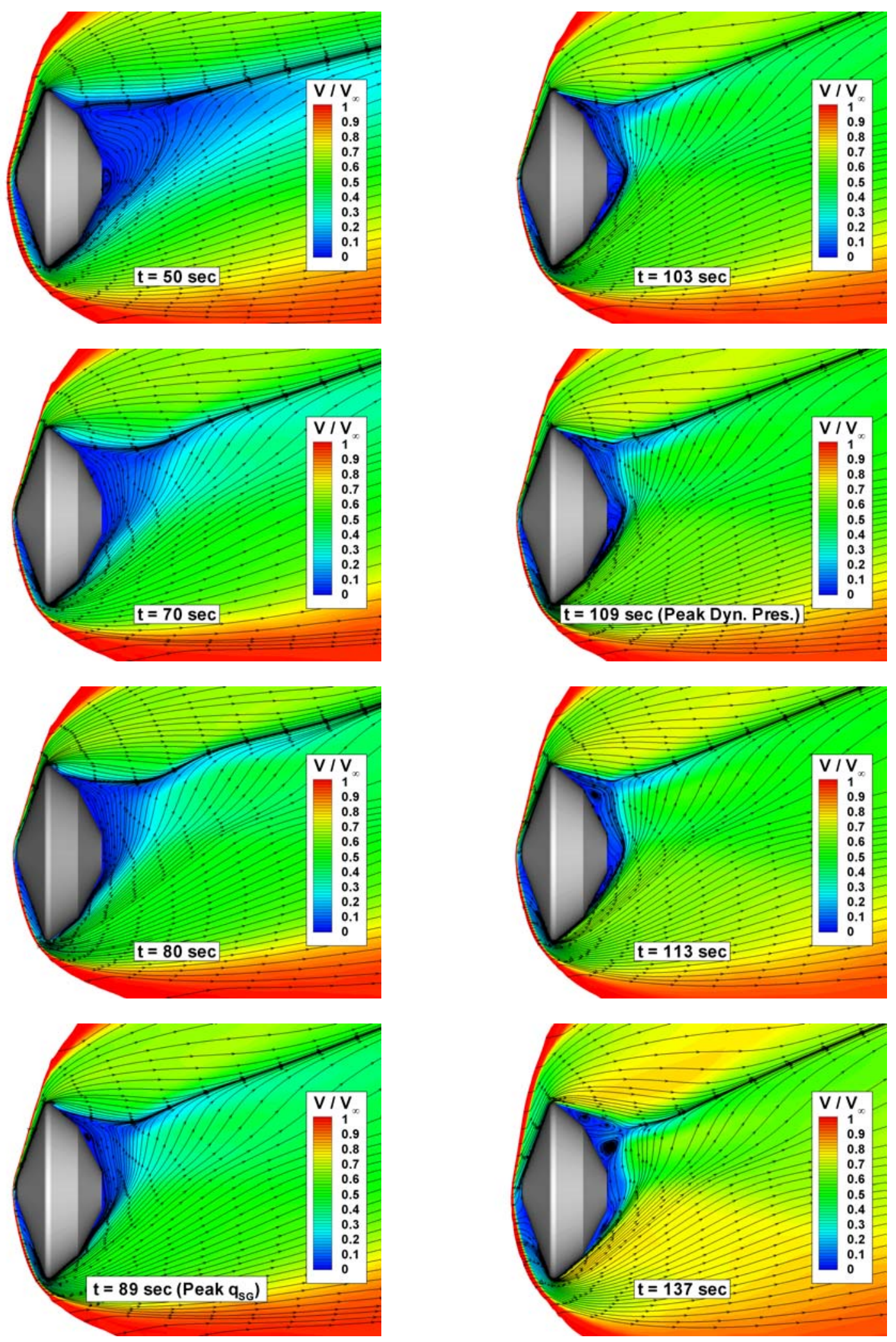

Figure 12. Computed Symmetry Plane Streamlines and Normalized Velocity Contours Along the Reference Trajectory (Grid 1) 


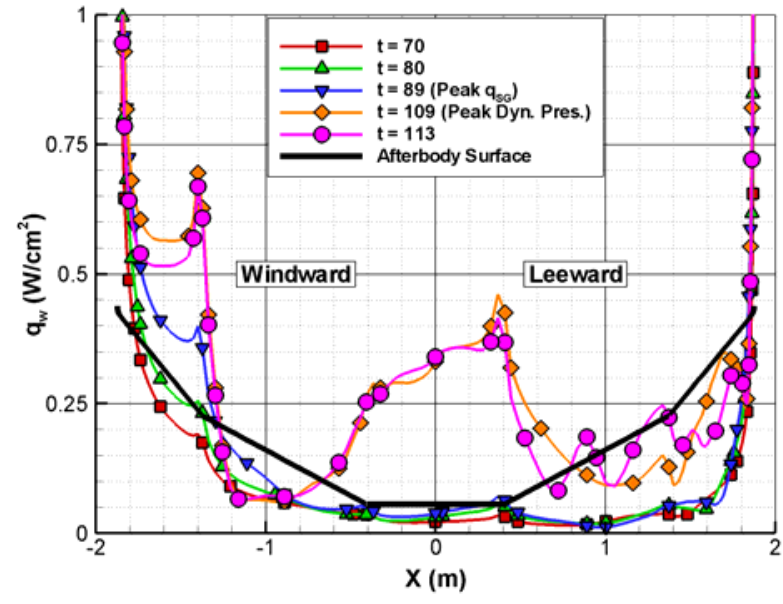

Figure 13. Computed Afterbody Symmetry Plane Heating Rates on Grid 1

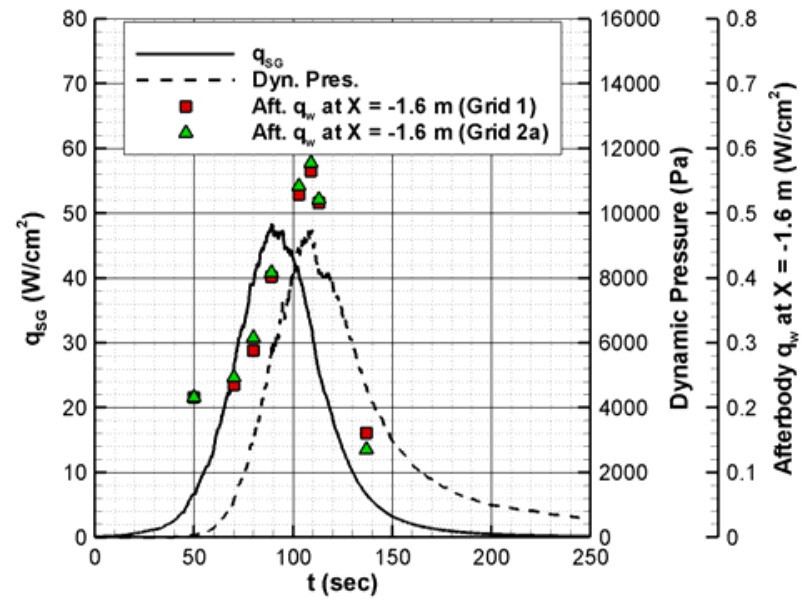

Figure 15. Reference Heating Rate, Dynamic Pressure, and Computed Afterbody Symmetry Plane Heating Rates at $\mathrm{X}=-\mathbf{1 . 6} \mathrm{m}$

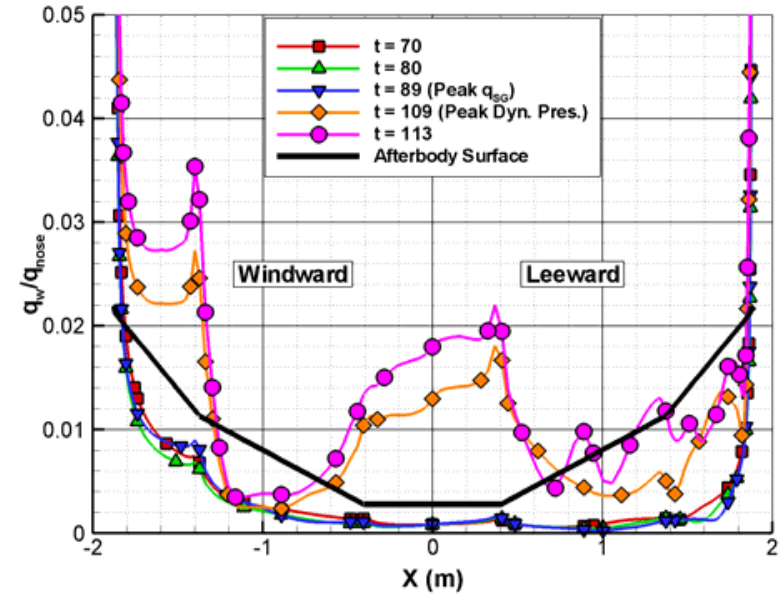

Figure 14. Computed Afterbody Symmetry Plane Heating Rates Normalized by Nose Cap Laminar Heating Rate on Grid 1

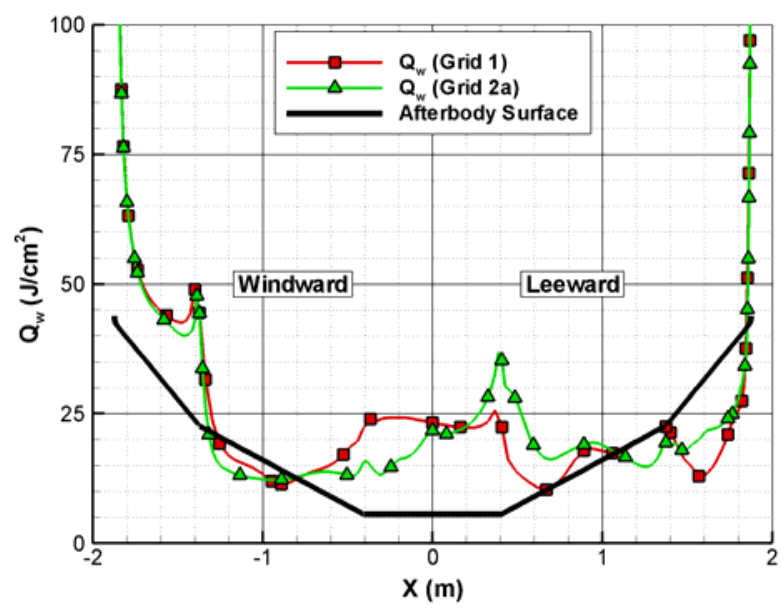

Figure 16. Computed Afterbody Symmetry Plane Total Heat Load

\section{Summary and Conclusions}

Computational afterbody heating predictions were obtained for a candidate Mars Science Laboratory entry aeroshell designed to fly at a trim angle of attack of $11 \mathrm{deg}$. The reference aeroshell is a 70-deg sphere-cone geometry with a biconic afterbody that is derived from the Viking entry vehicle. Flight predictions for a 2010 Mars arrival were computed with the LAURA code using an 8-species Mars gas in thermo-chemical non-equilibrium. Laminar solutions were obtained at several solutions along a reference trajectory resulting in the 3-sigma high integrated heat load. Afterbody heating rate reaches its maximum value near $0.6 \mathrm{~W} / \mathrm{cm}^{2}$ on the first windward afterbody cone at the time of peak freestream dynamic pressure. Computations on a baseline mesh and a mesh with double the resolution in each direction produce similar heating results. Afterbody heating rates are predicted to be generally less than $3 \%$ of the laminar heating rate on the forebody nose cap. 


\section{Acknowledgments}

The author would like to acknowledge contributions from the following people at NASA Langley Research Center: Scott Striepe and David Way for generating entry trajectories; Brian Hollis and Derek Liechty for providing experimental data; Steve Alter for generating the baseline computational grid.

\section{References}

${ }^{1}$ Lockwood, M. K., Powell, R. W., Graves, C. A., and Carman, G. L., "Entry System Design Considerations for Mars Landers," AAS 01-023, AAS Guidance and Control Conference, Breckenridge, CO, Jan.-Feb. 2001.

${ }^{2}$ Lockwood, M. K., Sutton, K., Prabhu, R., and Powell, R. W., "Entry Configurations and Performance Comparisons for the Mars Smart Lander," AIAA Paper 2002-4407, AIAA Atmospheric Flight Mechanics Conference \& Exhibit, Monterey, CA, Aug. 2002.

${ }^{3}$ Edquist, K. T., and Alter, S. J., "Computational Aeroheating Predictions for Mars Lander Configurations," AIAA Paper 2003-3639, AIAA Thermophysics Conference, Orlando, FL, June 2003.

${ }^{4}$ Edquist, K. T., Liechty, D. S., Hollis, B. R., Alter, S. J., and Loomis, M. P., "Aeroheating Environments for a Mars Smart Lander," AIAA Paper 2002-4505, AIAA Atmospheric Flight Mechanics Conference \& Exhibit, Monterey, CA, Aug. 2002.

${ }^{5}$ Liechty, D. S. and Hollis, B. R., "Heat Shield Cavity Parametric Experimental Aeroheating for a Proposed Mars Smart Lander Aeroshell," AIAA Paper 2002-2746, AIAA Fluid Dynamics Conference \& Exhibit, St. Louis, MO, June 2002.

${ }^{6}$ Hollis, B. R. and Liechty, D. S., "Boundary Layer Transition Correlations and Aeroheating Predictions for Mars Smart Lander," AIAA Paper 2002-2745, AIAA Fluid Dynamics Conference \& Exhibit, St. Louis, MO, June 2002.

${ }^{7}$ Liechty, D. S. and Hollis, B. R., "Control Surface and Afterbody Experimental Aeroheating for a Proposed Mars Smart Lander," AIAA Paper 2002-4506, AIAA Atmospheric Flight Mechanics Conference \& Exhibit, Monterey, CA, Aug. 2002.

${ }^{8}$ Hollis, B. R., Liechty, D. S., Wright, M. J., Holden, M. S., Wadhams, T. P., MacLean, M., and Dyakonov, A., "Transition Onset and Turbulent Heating Measurements for the Mars Science Laboratory Entry Vehicle," AIAA Paper 2005-1437, AIAA Aerospace Sciences Meeting \& Exhibit, Reno, Nevada, Jan., 2005.

${ }^{9}$ Ingoldby, R. N., Michel, F. C., Flaherty, T. M., Doryand, M. G., Preston, B., Villyard, K. W., and Steele, R. D., "Entry Data Analysis for Viking Landers 1 and 2 Final Report," NASA CR-159388, Martin Marietta Corp., Denver Div., Nov. 1976.

${ }^{10}$ Wright, M. J., Milos, F. S., and Tran, P., "Survey of Afterbody Aeroheating Flight Data for Planetary Probe Thermal Protection System Design,” AIAA Paper 2005-4815, AIAA Thermophysics Conference, Toronto, Canada, June 2005.

${ }^{11}$ Flaherty, T., “Aerodynamics Data Book VER-10,” TR-3709014 Rev. D, Martin Marietta Corp., Denver Div., June 1972.

${ }^{12}$ Cheatwood, F. M. and Gnoffo, P. A., "User's Manual for the Langley Aerothermodynamic Upwind Algorithm (LAURA)," NASA TM-4674, Apr. 1996.

${ }^{13}$ Papadopoulos, P., Prahbu, D., Olynick, D., Chen, Y. K., and Cheatwood, F. M., "CFD Code Validation and Comparisons for Mars Entry Simulations,” AIAA Paper 98-0272, AIAA Aerospace Sciences Meeting \& Exhibit, Reno, NV, Jan. 1998.

${ }^{14}$ Queen, E. M., Cheatwood, F. M., Powell, R. W., Braun, R. D., and Edquist, C. T.: "Mars Polar Lander Aerothermodynamic and Entry Dispersion Analysis,', Journal of Spacecraft and Rockets, Vol. 36, No. 3, May-June, 1999.

${ }^{15}$ Park, C., Howe, J. T., Jaffe, R. L., and Candler, G. V., "Review of Chemical-Kinetic Problems of Future NASA Missions, II: Mars Entries," Journal of Thermophysics and Heat Transfer, Vol. 8, No.1, Jan.-Mar. 1994.

${ }^{16}$ Roe, P. L., "Approximate Reimann Solvers, Parameter Vectors and Difference Schemes," Journal of Computational Physics, Vol. 43, No. 2, 1981.

${ }^{17}$ Yee, H. C., "On Symmetric and TVD Upwind Schemes," NASA TM-86842, September 1985.

${ }^{18}$ Steinbrenner, J. P. and Chawner, J., "Gridgen's Implementation of Partial Differential Equation Based Structured Grid Generation Methods", Proceedings, 8th International Meshing Roundtable, South Lake Tahoe, CA, Oct. 1999.

${ }^{19}$ Sorenson, R. L. and Alter, S. J., "3DGRAPE/AL: The Ames/Langley Technology Upgrade", Surface Modeling, Grid Generation, and Related Issues in Computational Fluid Dynamic (CFD) Solutions, NASA CP-3291, May 1995.

${ }^{20}$ Alter, S. J., "The Volume Grid Manipulator (VGM): A Grid Reusability Tool”, NASA CR-4772, Apr. 1997.

${ }^{21}$ Brauer, G. L., Cornick, D. E., and Stevenson, R., "Capabilities and Applications of the Program to Optimize Simulated Trajectories (POST)," NASA CR-2770, Feb. 1987.

${ }^{22}$ Spencer, D. A., Blanchard, R. C., Thurman, S. W., Braun, R. D., Peng, C.-Y., and Kallemeyn, P. H., "Mars Pathfinder Atmospheric Entry Reconstruction," AAS Paper 98-146, AAS/AIAA Space Flight Mechanics Meeting, Monterey, CA, Feb., 1998.

${ }^{23}$ Schoenenberger, M., Cheatwood, F. M., and Desai, P. N., "Static Aerodynamics of the Mars Exploration Rover Entry Capsule," AIAA Paper 2005-0056, AIAA Aerospace Sciences Meeting \& Exhibit, Reno, NV, Jan., 2005.

${ }^{24}$ Sutton, K. and Graves, R. A., "A General Stagnation-Point Convective-Heating Equation for Arbitrary Gas Mixtures," NASA TR R-376, Nov., 1971. 